\title{
HEAD INJURIES FROM THE OPHTHALMOLOGIST'S VIEWPOINT:
}

\author{
BY \\ Captain ARTHUR D. ECKER \\ and \\ Captain 'Eugene W. Anthony \\ MEDICAL CORPS, ARMY OF THE UNITED STATES
}

INCREASED mechanization of both civilian and military activities has yielded a large number of blunt head injuries. Instead of presenting a systematic review of the ocular evidence of head trauma ${ }^{1}$ the present paper will touch on some of the newer concepts concerning such injuries which may be of interest to the consulting ophthalmologist. First comes the importance of the ' proper state of mind in which to approach such patients.

\section{Prophylactic psychotherapy}

The picture of the late results of blunt head injury has been painted blacker than it really is ${ }^{2}$. The vast majority of both civilian $^{3}$ and military ${ }^{4}$ personnel return to their full duties in a matter of weeks, under proper manágement. The most important treatment in these cases is what has been called prophylactic psychotherapys. The patient must not be frightened. Many physicians forget that head injury is an acute emotional as well as an acute physical crisis. Fear may be transmitted to a suggestible patient by a gesture or tone of voice, and unduly prolong an otherwise brief convalescence. Let us approach these patients in an attitude of calm reassurance.

\section{Hutchinson's pupil and the tentorial pressure cone}

The fixed dilated pupil of Hutchinson, while uncommon, is of great importance. In this condition, involving the pupillomotor fibres of the third cranial nerve, the pupil is fully dilated and does not contract when a bright light is shone into it or into the opposite eye. If, on the other hand, the consensual light reflex is present, one may be dealing with an eye blinded by intra-ocular haemorrhage or severance of its optic nerve.' But the fixed dilated pupil is an infallible sign of raised intracranial pressure ${ }^{6}$. It is usually due to a laterally placed intracranial lesion of the same side, which most often is in the temporal but may be in the frontal or parietal lobe. The pupillary change is caused by herrniation of

* Received for publication, August 2, 1944. 
the medial part of the temporal lobe into the tentorial notch, the so called tentorial pressure cone $e^{7}$. This herniated portion of temporal lobe is said to pinch the ipsilateral oculomotor nertve, but is more likely to act by displacing and rotating the midbrain in such a way as to exert traction on the nerve. In any event, the resulting dysfunction of the nerve affects its pupillomotor fibres before obvious impairment of the nerve bundles to the extra-ocular muscles.

The underlying lesion may be a haematoma of any type, epidural, subdural, intracerebral or even contusion and swelling of the brain. This same mechanism may progress to compression of the mid-brain and occlusion of the aqueduct, thus leading to acute internal hydrocephalus and papilloedema ${ }^{8}$. If the process is slow, there may result on the same side as the lesion, hemiplegia, which is caused by:impingement against the tentorial notch of the contralateral pyramidal fibres in the mid-brain above their decussation. Below this level, in the medulla, they cross over to the side of the haemorrhage. Thus, the association of a dilated fixed pupil with a homolateral hemiplegia of late onset is indication for intracranial exploration on the same side.

\section{The mid-brain syndrome}

Bilaterally dilated fixed pupils soon after a head injury indicate a bad but not hopeless prognosis. If they are associated with neurogenic hyperthermia, rapid pulse, quickly rising rectal temperature, with a cold skin and decerebrate rigidity, there is damage to the mid-brain. The prompt intravenous administration of plasma and deliberate cooling of the skin may result in dramatic improvement ${ }^{8}$. Recently the intravenous use of soluble pentobarbital has been recommended for such states 9 .

\section{Argyll Robertson pupils of traumatic origin}

It is worth recalling that Argyll Robertson pupils may result from head injury. The lesion in these cases may be either in the central nervous system itself or in the peripheral efferent pathway to the pupil. In the latter case only one eye is likely to be affected, and the lesion is presumably in the region of the ciliary ganglion, through which run the nerve fibres for the light reflex. On the other hand, the nerve fibres concerned in the accommodationconvergence reflex probably run from the oculomotor nerve, perhaps along 'with the branch to the inferior oblique muscle and then to the ciliary muscle, without passing through the ciliary gainglion ${ }^{10}$. 


\section{Lesions of the temporal lobe}

In the study of lesions of the temporal lobe, one can use routine clinical study, roentgenologic methods (including plain films, ventriculograms and cerebral angiograms), as well as observation of the following functions : $(\dot{a})$ visual fields; $(b)$ speech (if the temporal lobe of the dominant hemisphere is under consideration); (c) electro-encephalograms; $(d)$ caloric nystagmus. Problems of perimetry will be mentioned later in this paper. It has been shown that the electro-encephalogram, when used as an index of active cerebral abnormality after a head injury, will help to estimate the extent of the cerebral damage ${ }^{11}$. There has been some work correlating electro-encephalographic changes in the occipital lobe with visual field defects. The electro-encephalogram has also been found helpful in the diagnosis of hysterical amblyopia. Directional preponderance of caloric nystagmus to the side of the lesion is present when the temporal lobe (but not other parts of the brain) is involved ${ }^{12}$. Thus, something of the function of a temporal lobe can be determined by tests in the ear of opposite side, even if the eardrum on the affected side is perforated.

\section{Extra-ocular muscles}

Due to the dominance of fusion, partial paralysis may go unnoticed unless examination of the extra-ocular muscles is done by some form of occlusion. The most simple form is the cover test which is easily performed, even with the patient in bed, by means of a flashlight bulb and a folded piece of paper. Should there be phoria in any of the six cardinal positions, prisms may be used to detèrmine the field of greatest deviation, and the affected nerve or muscle may be designated. If of sufficient amount; the paralysis gives rise to double vision, and in these cases charting the diplopia fields is useful in following recovery.

The location and nature of the neural lesion in any muscular palsy is of interest. When recovery occurs within a matter of days, the nerve has been injured in a process akin to concussion; whereas if months are required, presumably the axons have been torn and have regenerated in an intact nerve sheath." If no recovery occurs one can assume either severance of the nerve, severe damage to its blood supply, or such firm scarring that regeneration is prevented. The mechanism of these injuries may well be traction on the nerve by the shift of cranial contents at the time of injury. Since the rate of regeneration of human nerves is about $1.5 \mathrm{~mm}$. a day, after a latent period of 30 days, the approximate site of the lesion may be calculated from the time of recovery. Furthermore, individual muscles, especially the oblique, may be 
affected at or near their attachment to the orbit, and in such cases fracture of the bone is to be suspected.

Patients who have suffered from head injuries frequently complain of blurring of near vision during convalescence. They seem unduly concerned about their eyes and frequently seem to have difficulties of accommodation. When they are encouraged to use their eyes and to resume normal physical activities, these complaints usually disappear promptly. For the relatively few patients whose accommodation or convergence are subnormal, as tested objectively, exercises are indicated. These may consist of simple convergence movements stimulated by a pencil and gradually prolonged periods of reading. Furthermore, in cases of paralysis of one or more extra-ocular muscles, orthoptic exercises should be encouraged. "Even in the instance of a completely paralyzed muscle, these procedures, acting on the other extraocular muscles, will' result in passive movement of the affected muscles and improvement in its blood supply. Such activities help prevent atrophy of the affected muscle and contracture of the antagonist while the nerve is regenerating.

\section{Visual fields}

Study of the fields is of importance in head injuries when the patient is able to co-operate for rough tests, and even more so when he is able to sit up and face the perimeter and tangent screen. Fields should be determined with test objects yielding various visual angles in order to learn something of the activity of the lesion which is affecting the visual pathway. This activity will be gauged not only by the slope of the field at any one time, but also by changes in the field from time to time.

Involvement of the optic nerve at the time of injury may result in variable amounts of visual loss, and is probably due to involvement of the blood supply. A late effect of trauma to the optic canal is overgrowth of bone callus, which can be recognized early only by the use of quantitative field studies. There may be annular scotomata in these cases ${ }^{13}$.

The optic chiasm may be affected in head injury probably due to damage of small vessels and ischaemia of the nerve fibres ${ }^{14}$. The most characteristic perimetric changes are bilateral temporal field loss or total blindness in one eye and temporal loss in the other. Other changes may be quadrantic or scotomatous, especially if the lesion is near the anterior chiasmal angles, where involvement of the upper temporal field of the opposite eye is due to a lesion of the " knee " of crossed fibres coming from the inferonasal portion of the retina ${ }^{15,16}$. With obvious field changes in one eye (including blindness) it is, therefore, especially important to do a complete field study of the other side. 
Perimetric changes may be sfowly progressive from the start, or may appear later as a result of chiasmal adhesions, so-called traumatic arachnoiditis. The field changes in such lesions are not characteristic but a central scotoma with a hemianopic defect of the peripheral visual field, especially if bitemporal is suggestive ${ }^{17}$. It is most important to remember that changes for the worse which occur some time after the original injury are evidence of an active pathological process. Operative intervention in such cases is often gratifying ${ }^{16}$.

Damage to the radiations causes - incongruous homonymous visual field defects whereas occipital lobe lesions are congruous. Visual field studies in cases of blunt trauma to the frontal region have demonstrated injury to the occipital lobes which might otherwise have gone unnoticed. These changes may be transitory and manifest only in the first few weeks following the trauma. In other cases the defects are permanent, and are usually in the form of small homonymous scotomata near the central area. The probable mechanics of such injury, rotation of the skull in the horizontal plane, has been recently illustrated ${ }^{18}$.

The presence of normal visual fields does not exclude the possibility of a slowly growing subdural haematoma overlying the optic radiation. Although such a lesion is intracranial, it is actually outside the brain substance and may progress so slowly as not to impair the function 'of the nerve tracts. Thus; there is significance in the presence of normal visual fields in a case of suspected subdural. haematoma with significant lateral shift of the pineal body, or appropriate changes in the spinal fluid ${ }^{19}$.

\section{Summary}

The basis for a few ophthalmic syndromes associated with closed head injuries has been presented in the light of modern neurology. Special attention has been given to disturbances of the pupils, extra-ocular muscles, and visual fields.

\section{RFFERENCES}

1. LYLE, D. J-Eye manifestations of head injuries. Ji. Amer. Med. Assoc., Vol: CXXIII, 14, pp. 873-879, December 4, 1943. (See also BURCH, F. E., Ocular evidence of head trauma. Wisconsin Med. Jl.m.1942).

2. CAIRNS, HUgh.-Planning for treatment of head injuries. Brit. Med. Jl., 4288, pp. 313-314, 1943. 3. GutTmAN N ERIC.-Post-contusional headache. Lancet, p. 10, January 2,

4. SYMONDS, C. P. and RUSSELL, W. R.-Accidental head injuries in service patients, Lancet, January: $2,1943$.

5. DENNY-BROWN, DEREK. - The principles of treatment of closed head injury, Bull. of N.Y. Acad. of Med., Vol. XIX, pp. 3-16, 1942 .

6. RowbothAM, G. F.-Acute injuries of the head. Williams \& Wiltins, Baltimore, 1942.

7. JEFFERSON, GEOFFREY.-The acute head as a neurological problem. Glas. Med. Jl., Vol., XX, p. 77, 1942. 
8. ECKER, ARThUR.-Treatment of high fever following head injury and suggestion concerning ventricular drainage for acute traumatic hydrocephalus. The Military Surgeon, Vol. XCI, pp. 670-675, 1942.

9. Beaton, L. E.-Neurogenic hyperthermia and its treatment with soluble pentobarbital in the monkey. Arch. Neur. and Psych., Vol. XLIX, pp. 518-547, 1943.

10: NAThan, P. W. aud TURner, J. W. A. - The efferent pathway for pupillary contraction. Brain, Vol. LXV, pp. 343-352, 1942.

11. Williams, Denis. - The electro-encephalon $\mathrm{m}$ in acute head injuries. Jt. Neur. and Psych., Vol. IV, pp. 107-13r, 1941.

12. FitzGERALD, GERALD and HALLPIKE, C. S.-Studies in human vestibular function. 1. Observations on the dirctional preponderance (Nystagmusbereitschaft) of caloric nystagmus resulting from cerebral lesions. Brain Vol. LXV, pp. 115-138, 1942.

13. LILLIE, W. I. and ADSON, A. W.-Unilateral central and annular scotoma produced by callus from fracture extending into optic canal. Arch. of Ophthal., Vol. XII, p. 500, 1934.

14. Traguair, H. M., DotT, N. R. and Russell, W. R.-Traumatic leșions of the optic chiasma. Brain, Vol. LVIII, p. 398, 1935.

15. Traquair, H. M.-An introduction to clinical perimetry. Kimpton, London. 1942.

16. Hughes, E. B. C.-Injury to optico-chiasmal junction. A case report. Brit. Jl. Ophthal., Vol. XXVII, 8, pp. 367-371, 1943.

17. VAIL, DERRICK.-Syphilitic opticochiasmic arachnoiditis. Amer. Jl. Ophthal., Vol. XXII, p. 505, 1939.

18. HoubouRN, A. H. S.-Mechanics of head injuries. Lancet, p. 438, October 9 , 1943.

19. ECker, ARthur D. and Anthony, EUgene, W.-Exanopic central scotomaa pitfall in diagnosis. (To be published).

\section{TRANSPARENCY OF THE LENS FOLLOWING TRAUMATIC CATARACT*}

BY

Major H. J. STERN, R.A.M.C.

Ir is well known that the typical posterior cortical cataract due to contusion or perforation of the lens sometimes clears up completely. This particular form of opacity in the lens depends on the entrance of fluid underneath the capsule and between the lens fibres. The vacuoles thus formed are of a refractive index different from the lens substance and the lens appears opaque although its fibres are still transparent. At this stage the vacuoles may be absorbed and the "cataract" appears to resolve.

The case to be described presents a most unusual picture in addition to this phenomenon.

A West African negro, aged 25 years, presented himśelf in the out-patient department with a note from his Medical Officer saying that his left eye had been injured by a flying particle of stone. The report stated that the stone splinter had been seen in the cornea and that a small hyphaema had been present. At the time of the examination, however, several hours after the

\footnotetext{
*. Received for publication, September 29, 1944.
} 